\title{
Perspectives of Healthcare Professionals Toward Interprofessional Collaboration in Primary Care Settings in a Middle Eastern Country
}

This article was published in the following Dove Press journal: Journal of Multidisciplinary Healthcare

\author{
Alla El-Awaisi (1D) \\ Ahmed Awaisu (1D' \\ Shimaa Aboelbaha' \\ Zeinab Abedini' \\ Jessie Johnson (1D ${ }^{2}$ \\ Samya Ahmad Al-Abdulla (iD ${ }^{3}$ \\ 'Department of Clinical Pharmacy and \\ Practice, College of Pharmacy, QU \\ Health, Qatar University, Doha, Qatar; \\ ${ }^{2}$ Faculty of Nursing, University of Calgary \\ Qatar, Doha, Qatar; ${ }^{3}$ Department of \\ Clinical Operations, Primary Health Care \\ Corporation, Doha, Qatar
}

Correspondence: Alla El-Awaisi Department of Clinical Pharmacy and Practice, College of Pharmacy, QU Health, Qatar University, Doha, Qatar Email elawaisi@qu.edu.qa
Background: Primary healthcare (PHC) setting is regarded as a central pillar to the healthcare system as it tends to be the first point of contact for patients. Interprofessional collaboration between healthcare professionals (HCP) in PHC settings remains unexplored in the Middle East.

Aim: The objective of this study was to explore the perspectives of HCP in PHC centers towards interprofessional collaboration and to identify the facilitators and the barriers to collaborative practice.

Methods: A cross-sectional, web- and paper-based survey involving HCP in PHC centers was conducted in Qatar. Descriptive statistics as well as Student's $t$-test and One Way ANOVA test were performed to determine statistical differences in Readiness for Interprofessional Learning (RIPLs) scores between demographic groups.

Results: Overall, 1415 participants out of a potential $2500 \mathrm{HCP}$ practicing in Qatar completed the survey (response rate, 56.6\%). HCP generally indicated a positive attitude and readiness towards interprofessional collaboration. Furthermore, physicians had slightly more positive readiness towards understanding their professional identity than other healthcare professionals. Participants with previous interprofessional collaboration or interprofessional education experiences exhibited greater, but non-significant positive attitudes toward interprofessional collaboration compared to those without previous experiences. Identified barriers and facilitators included are conceptual rather than structural. Facilitating factors included HCP readiness and perceived benefit of interprofessional collaboration effectiveness in the work setting, increased professional satisfaction, respect between healthcare professions, appreciation of others' contribution, leadership, and institutional support. Top perceived barriers included leadership and support, time commitment, and resources constraints. Conclusion: HCP in PHC settings have demonstrated the willingness and readiness to engage in interprofessional collaboration. Recent reforms within the PHC setting consist of promoting interprofessional teams and collaborative culture. However, it is imperative to provide training and education to foster and support interprofessional collaborative practices.

Keywords: interprofessional collaboration, primary health care, healthcare professionals

\section{Introduction}

As healthcare systems advance toward improving the quality and efficiency of health services, the need for collaborative efforts between healthcare professionals (HCP) of different disciplines increases. Therefore, HCP need to acquire the requisite competencies and develop the skills needed to work together effectively 
in order to positively impact patient care outcomes. As a result, in 2010, the World Health Organization (WHO) published a seminal document entitled, "Framework for Action on Interprofessional Education and Collaborative Practice". ${ }^{1}$ In this framework, WHO strongly advocated for the development of team-based collaborative models in different areas of healthcare to enhance the delivery of healthcare services. WHO defined interprofessional collaboration (IPC) in healthcare settings as occurring when multiple health workers from different professional backgrounds provide comprehensive services by working with patients, families, carers and communities to deliver the highest quality of care across settings. Key concepts of collaboration stem from shared responsibilities, collective decisions, interprofessional communication, accountability, and education. ${ }^{2}$ Therefore, collaboration involves HCP, with different backgrounds, working collaboratively in a synergistic rhythm to address patient needs and improve patient care outcomes. ${ }^{3}$ Six key criteria are required for effective collaborative practice as stipulated in the Canadian National Interprofessional Competency Framework and these include interprofessional communication, team function, collaborative leadership, confidence in own professional role, knowledge of other healthcare team roles and responsibilities, and negotiation skills for conflict resolution while working towards patient/client/ family/community-centred care. ${ }^{4,5}$ Collaborative practice has a myriad of benefits represented in terms of organizational, healthcare team, patient, and healthcare professional benefits. ${ }^{6-13}$ The WHO framework further highlights that IPC leads to the strengthening of healthcare systems, optimization of healthcare services, and improvement in health outcomes and quality of patient care, which are usually the prime motivators for institution team-based care. ${ }^{1}$ In addition, IPC results in a higher level of patient satisfaction, better acceptance of care and improved health outcomes in both acute and primary healthcare (PHC) settings. ${ }^{6}$ Furthermore, it has been suggested that miscommunication and lack of collaboration have a negative impact on healthcare system and health outcomes and are a primary cause of preventable errors to patients and impairment of quality of care. ${ }^{12,14}$

PHC setting is regarded as a central pillar to the healthcare delivery system as it tends to be the first point of contact for many patients. ${ }^{15}$ Furthermore, with the increased complexity of healthcare needs in PHC, there is a need for more and efficient IPC, which is essential for providing quality services, achieving better health outcomes and patients' satisfaction, and improving job satisfaction amongst HCP. ${ }^{15-17}$ A systematic review to identify studies that test associations between policy (macro), organizational (meso), care team (micro) and individual factors, and collaboration in interprofessional primary care teams, proposed a conceptual model at these various levels. ${ }^{18}$ It was found that more than $70 \%$ of the identified factors were at the micro-level where actions could be targeted to improve IPC in primary care teams. These factors, which are key considerations within the healthcare team in PHC, were grouped into formal processes through audits and having a team vision, social processes through open communication and supportive colleagues, team attitude in feeling part of the team and team structure. ${ }^{18}$ However, collaboration and teamwork in PHC is often much more complex than it appears and needs to be planned and resourced to ensure the goals of the collaboration are achieved. ${ }^{19}$ IPC is being viewed as an integrative cooperation of different HCP, blending complementary competence and skills for the patients' benefits while making the best use of resources. ${ }^{15,20}$ Interprofessional primary care teams are been promoted over the traditional physician-led team-based care and have been shown to improve collaboration. ${ }^{18,21}$ Many PHC settings have moved towards the implementation of new models of care such as family medicine groups, with interprofessional collaboration central to its goal. ${ }^{22}$ To develop effective IPC strategies in practice settings, it is essential to investigate the attitudes of HCP towards collaboration since positive attitudes are essential to the successful implementation of IPC. ${ }^{23}$ Furthermore, challenges and barriers need to be identified and appropriately addressed to successfully establish a collaborative environment. ${ }^{24}$ The drivers of IPC include HCP' mutual interest in collaboration, potential opportunities to improve the quality of patient care, and enhancement of practice experiences. ${ }^{20}$ Conversely, barriers to IPC include lack of awareness of other HCP' roles, responsibilities and scope of practice, confidentiality, and lack of interprofessional training. ${ }^{20}$

IPC among HCP in the Middle East remains unexplored in the literature with a few studies focusing on collaboration between two professions such as physicians and nurses collaboration, ${ }^{25}$ while some focused on physicians and pharmacists collaboration. ${ }^{26-28}$ Furthermore, little is known about the perception of HCP in PHC settings in Qatar towards IPC. One study explored the perspectives of practicing pharmacists towards interprofessional education (IPE) and collaborative practice in various settings in Qatar. ${ }^{29}$ The study highlighted reports of collaboration emerging in some hospitals, recent development in PHC settings, and lack of 
collaborative practice in community pharmacies. Nevertheless, pharmacists in that study demonstrated readiness for IPC. Another study explored physicians' perceptions of pharmacist's roles in PHC settings in Qatar which showed physicians were more comfortable with pharmacists' activities focused on product rather than clinical-based collaborative activities. ${ }^{30}$ This, however, is contrary to physicians' perception in tertiary hospitals, where they reported familiarity with and support to pharmacists' clinical roles. ${ }^{31}$

With the initiatives of integrating IPE into different healthcare professional education curricula, which is instrumental to shaping the effectiveness of collaborative practice, the call for promoting an IPC practice culture across the different healthcare settings in an ever-increasing complex healthcare system is rapidly evolving. IPE on its own is not enough to ensure optimal health services are achieved. ${ }^{2}$ Therefore, the culture of IPC begins with IPE as the base, an initiative that has been integrated into the different healthcare professional education curricula in Qatar over the last 5 years. ${ }^{32}$ It is hoped that once these students graduate, they will be able to translate what they have learnt into practice and apply collaborative practice principles. Given the emphasis on IPE within educational settings, the need to understand how IPC is practiced within PHC settings is crucial. It is believed that positive perceptions among HCP are facilitating factors for IPC and hence the importance of understanding and exploring the perspectives of $\mathrm{HCP}^{20}$ WHO emphasized that mechanisms that shape collaborative practice are not the same in all health systems and hence recommendations need to be appropriate for the regional context studied. ${ }^{1}$ Understanding the regional context which may be different from international literature will help to identify best practice models and formulate viable strategies for improving the current practice amongst all $\mathrm{HCP}$ in the PHC settings. The objectives for this study were to: 1) identify the current knowledge and awareness of HCP in Qatar relating to IPC; 2) determine the readiness and attitudes of HCP in Qatar towards IPC; 3) assess their interest in IPC training and their beliefs about IPC and; 4) identify potential facilitators and barriers to collaborative practice in Qatar.

\section{Methods Study Design}

This was a cross-sectional, web- and paper-based survey conducted in Qatar among PHC professionals between November 2017 and February 2018.

\section{Study Setting}

The study was conducted within the Primary Health Care Corporation (PHCC) in Qatar, which was established back in 1978 to provide comprehensive PHC services and became an independent body in 2012 with full administrative and financial autonomy. The advancement in the PHCC was due to the importance placed on the healthcare services provided through health centers, and in alignment with Qatar's National Health Strategy objectives, which emphasize that $\mathrm{PHC}$ is the base for health system in the country. $^{33,34}$ The PHCC is leading the transformation of the health and wellbeing of the people of Qatar by shifting the balance of care from curative, hospital-based treatment to enhanced preventive, health and wellness services in the community. Currently, the PHCC is operating through 27 PHC centers distributed across three regions in the country, namely the Central, Western, and Northern regions. Thirteen of these centers are located in Doha city, while the rest of the centers are located in other populated areas across the country in order to provide a wide variety of healthcare services depending on the location and needs of each area. Each center is staffed with HCP who provide a broad range of services, focusing on health promotion and disease prevention. PHCC serves a large sector of Qatar's community populations including neonates, children and adolescents, adult, pregnant women, and those with chronic conditions. PHCC has adopted and implemented Family Medicine Model of Care and offers a wide range of services including: general medicine, dentistry, ophthalmology, optometry, ENT, dermatology, mental health; preventive and lifestyle services such as wellness, premarital care, cancer screening, gym and geriatric, physiotherapy and radiology services.

\section{Study Population and Sampling}

The study involved all HCP including physicians, dentists, pharmacists, nurses, dieticians, medical laboratory technologists, radiological technologists, physiotherapists and audiologists practicing in PHCC in Qatar. As of January 2018, there were about $2500 \mathrm{HCP}$ practicing in PHCC in Qatar. The Raosoft online calculator was initially used to determine the sample size needed for the study based on the following parameters: population size of HCP in PHC centers in Qatar $(n=2500)$, alpha level (margin of error) $(5 \%)$, confidence level (95\%), and sample response distribution $(50 \%)$. Based on the above assumptions, the minimum sample size required was 334 . The initial sampling plan 
was to utilize a probability sampling technique such as simple random sampling in order to minimize selection bias. However, we were unable to obtain a sampling frame due to confidentiality concerns; therefore, we used a universal sampling strategy where all HCP working in PHC centers were sent the survey. Furthermore, from our previous experiences of conducting survey research among HCP in Qatar, low response to surveys is a common occurrence. ${ }^{29,35}$ Hence, we targeted and distributed the survey to all HCP that were reachable in the 23 PHC centers through the respective manager at each center. HCP working in PHC centers were eligible to be included in the study if they have direct encounters with patients as part of their primary role and if they could speak English.

\section{Survey Instrument Development and Validation}

The 30-question survey instrument was developed based on the objectives of the study and through adaptation of related surveys: the Readiness for Interprofessional Learning Scale (RIPLS) ${ }^{36}$ and the Survey of Interprofessional Collaboration Learning Needs and Training Interest in Health Professionals, Teachers, and Students. ${ }^{37}$ The modified RIPLS scale used was previously validated to assess HCP' readiness for interprofessional learning and had been appropriately tested for psychometric properties with a reported internal consistency reliability (Cronbach's alpha coefficient) of $0.76 .{ }^{36}$ The same survey was used among practicing pharmacists in Qatar, with a reported Cronbach's alpha coefficient of 0.809 for the RIPLS scale. ${ }^{29}$ Further questions were added to meet the study's objectives, including identified facilitators and barriers and these were based on published literature and on the expertise of the research team to provide a broader perspective on the topic. There were opportunities for participants to add in free-text responses. Definitions of terms such as IPC and interprofessional interactions were added to relevant sections to enable participants to distinguish between such terms and avoid confusion. Furthermore, in the introductory page, participants were provided with definitions for some relevant terms including collaborative practice.

The initial draft of the questionnaire underwent content validity by two pharmacy and one nursing faculty members with expertise in IPE research and questionnaire development. The team anonymously agreed to use the questions adapted from RIPLS without modifications, because it was a previously validated tool that suited the study objectives and setting. On the other hand, some modifications were made to the other questions through an iterative process. The modified draft of the questionnaire was designed and uploaded on SurveyMonkey ${ }^{\circledR}$, a professional tool for developing web-based surveys (SurveyMonkey Inc., Palo Alto, CA). In order to preserve our sampling population, this version of the survey underwent face validity by a sample of HCP working in Hamad Medical Corporation to test its burden (completion time), readability, clarity, and comprehensiveness of its items. This sample was purposively selected based on our knowledge of their ability to provide useful feedback and were known to members of the research team.

Amendments were made regarding the organization and clarity of some questions based upon the pilot respondents' feedback. Some of the changes included putting the Likert scales in the same order, changing Likert-type scale options to be more consistent with the questions, fixing technical problems related to the web link itself, and changing order of some questions for clarity purposes. The final version of the questionnaire was developed through an iterative process among four of the study investigators. The final version of the questionnaire contained 30 questions comprising 77 items. These include multiple-choice questions, Likert-type rating scales, and open-ended questions, divided into the following six sections: (A) Participant's characteristics (10 items); (B) Awareness, experience, and knowledge about IPE and collaborative practice (14 items); (C) Readiness for Interprofessional Learning Scale (RIPLS) that included three subscales (patient-centeredness, sense of professional identity, teamwork and collaboration) (23 items); (D) Beliefs about IPC (7 items); (E) Interest in interprofessional learning (9 items); (F) Facilitators and barriers toward collaborative practice (14 items).

\section{Data Collection Procedures}

All eligible HCP working in PHCC in Qatar were invited to complete the online survey through an E-mail, sent through PHCC operations department, with an online link to the survey through the SurveyMonkey ${ }^{\circledR}$. It contained the study objectives and other details, ethical considerations, implied consent, and the web link to the survey. Respondents were informed through the link that participation in the study was voluntary and that the questionnaire was anonymous. Unfortunately, due to the very low response rate (10\%) after the 6 weeks of emailing the 
survey and sending two reminders, the research team was advised to distribute the survey as paper-based through the health center managers in the 23 PHC centers. Participants were informed not to fill the paper-based survey if they had already responded to the online survey. The paper based survey was collected by members of the research team 1 week after. The responses obtained through the paper-based survey were manually entered into the SurveyMonkey ${ }^{\circledR}$ link by three research assistants. The survey link was closed, and the data were exported from SurveyMonkey ${ }^{\circledR}$ (SurveyMonkey Inc., Palo Alto, CA) to IBM SPSS $^{\circledR}$, v.24 (IBM Corp, Armonk, NY). The majority of the participants $(78.8 \%, \mathrm{n}=1115)$ filled the paper survey instead of the online version.

\section{Data Analysis}

Statistical analyses of the collected data were performed using Statistical Package for Social Sciences, version 24 (IBM SPSS ${ }^{\circledR}$ Statistics for Windows; IBM Corp, Armonk, New York, USA). Both descriptive and inferential statistics were used for the data analyses. Frequencies and percentages were used to summarize the responses generated from categorical variables, while continuous data were presented as mean \pm SD. Student's $t$-test and One Way ANOVA test were used to determine differences between demographic and professional categories in terms of their readiness for interprofessional learning and collaboration. A $p$-value of $\leq 0.05$ was used to determine statistical significance. For open-ended questions, content analysis approach was used. ${ }^{38}$ Two of the researchers (SA and ZA) independently read and re-read the open answer responses to identify keywords. These were then sorted into themes. Results were discussed with and agreed upon by the other two team members ( $\mathrm{AE}$ and $\mathrm{AA}$ ).

\section{Results}

\section{Participants' Demographic and Professional Characteristics}

One thousand four hundred fifteen participants out of potential 2500 HCP working in PHCC responded to the survey (response rate, 56.6\%). Most commonly, participants were female $(63.8 \%, \mathrm{n}=904)$, Filipino $(30.2 \%$, $\mathrm{n}=428)$, nurses $(48.6 \%, \mathrm{n}=687)$, and aged between 25 and 33 years $(44.3 \%, n=627)$. The majority of participants have had 6-10 years of practice in their profession $(36.3 \%$, $\mathrm{n}=508$ ). Table 1 summarizes the participants' sociodemographic and professional characteristics.

\section{Awareness, Experiences, and Knowledge About Interprofessional Education and Collaboration}

Around $76 \%(n=1011)$ of the participants indicated that they regularly interact with other HCP most of the time, while $64 \%(n=847)$ indicated that they have actual collaboration with other HCP on a regular basis. Upon asking them about professionals they interact and collaborate the most with, physicians followed by nurses and pharmacists were the highest ranked for both categories (Table 2). Respondents also indicated that they have had previous experiences with collaborative practice $(60 \% ; n=771)$ and IPE $(81 \%, n=1062)$ as shown in Table 2.

Moreover, participants rated their personal knowledge and level of skills regarding collaboration in a multi-item scale question. Weighted averages were computed for the relevant sections using SurveyMonkey. The data were later exported into SPSS. The weighted average (WA) was used as a measure in this context with a maximum obtainable score of 5. Most participants rated "level of skills for communicating effectively" as the highest (WA: 4.10), followed by "level of skills in building a rapport" (WA: 4.03), and "level of skills in managing conflict of interest" (WA: 3.93). The least rated item was "knowledge about interprofessional collaboration models and research" (WA: 3.49), followed by "knowledge regarding team stages (storming, forming, norming, and performing)" (WA: 3.63).

\section{Readiness for Interprofessional Learning Survey (RIPLS)}

Since the reliability of the RIPLS among HCP was tested to be high in previous studies as shown above, a preliminary testing was not conducted. However, a confirmatory reliability testing was conducted to confirm this, and internal consistency reliability of the items was determined to be 0.881 . Below are the findings related to readiness for interprofessional learning among the HCP in this study.

\section{Subscale-I Teamwork and Collaboration}

This subscale contained 13 positive statements with a focus on teamwork and collaboration. It aimed to assess participants' willingness to become effective team members and their readiness to collaborate with each other. The majority of respondents reported a strong positive attitude toward teamwork and readiness to collaborate since they consistently selected either "agree" or "strongly agree" 
Table I Sociodemographic and Professional Characteristics of Healthcare Professionals Practicing in Primary Healthcare Centers in Qatar $(n=|4| 5)$

\begin{tabular}{|c|c|c|}
\hline Characteristics & $\begin{array}{l}\text { Frequency } \\
\text { (\%) }\end{array}$ & $\begin{array}{l}\text { Missing } \\
(n, \%)\end{array}$ \\
\hline $\begin{array}{c}\text { Gender* } \\
\text { Female } \\
\text { Male }\end{array}$ & $\begin{array}{l}904(63.8) \\
501(35.4)\end{array}$ & $10(0.8)$ \\
\hline $\begin{array}{l}\text { Age in years* } \\
\text { I8-24 } \\
25-33 \\
34-44 \\
45-54 \\
55-65 \\
\text { Older than } 65\end{array}$ & $\begin{array}{l}7(0.5) \\
627(44.3) \\
544(38.4) \\
182(12.9) \\
43(3.0) \\
3(0.2)\end{array}$ & $9(0.6)$ \\
\hline $\begin{array}{l}\text { Healthcare professional category* } \\
\text { Nurses } \\
\text { Pharmacists } \\
\text { Physicians } \\
\text { Medical laboratory technologists } \\
\text { Radiological technologists } \\
\text { Dentists } \\
\text { Dental assistant } \\
\text { Physiotherapist } \\
\text { Dietician } \\
\text { Others }\end{array}$ & $\begin{array}{l}687(48.6) \\
187(13.2) \\
167(11.8) \\
140(9.9) \\
88(6.2) \\
50(3.5) \\
37(2.6) \\
12(0.8) \\
6(0.4) \\
27(1.9)\end{array}$ & $14(\mathrm{I})$ \\
\hline $\begin{array}{l}\text { Years of experience* } \\
\text { Less than I } \\
1-5 \\
6-10 \\
11-15 \\
16-20 \\
\text { More than } 20\end{array}$ & $\begin{array}{l}19(1.3) \\
244(17.2) \\
508(35.9) \\
301(21.3) \\
191(13.5) \\
136(9.6)\end{array}$ & $16(1.1)$ \\
\hline $\begin{array}{l}\text { Country of origin* } \\
\text { Egypt } \\
\text { India } \\
\text { Jordan } \\
\text { Palestine } \\
\text { Philippines } \\
\text { Sudan } \\
\text { Qatar } \\
\text { Others }\end{array}$ & $\begin{array}{l}175(12.4) \\
361(25.5) \\
103(7.3) \\
42(3.0) \\
428(30.2) \\
92(6.5) \\
30(2.1) \\
167(11.8)\end{array}$ & $17(1.2)$ \\
\hline $\begin{array}{l}\text { Country of their first professional } \\
\text { degree* } \\
\text { Philippines } \\
\text { India } \\
\text { Egypt } \\
\text { Sudan } \\
\text { Jordan } \\
\text { Qatar }\end{array}$ & $\begin{array}{l}425(30.0) \\
368(26.0) \\
191(13.5) \\
63(4.5) \\
109(7.7) \\
51(3.6)\end{array}$ & $16(1.1)$ \\
\hline
\end{tabular}

(Continued)
Table I (Continued).

\begin{tabular}{|l|l|l|}
\hline Characteristics & $\begin{array}{l}\text { Frequency } \\
\text { (\%) }\end{array}$ & $\begin{array}{l}\text { Missing } \\
\text { (n, \%) }\end{array}$ \\
\hline $\begin{array}{l}\text { Palestine } \\
\text { Others }\end{array}$ & $\begin{array}{l}5(0.4) \\
187(13.2)\end{array}$ & \\
\hline $\begin{array}{l}\text { Years of practice in PHCC in Qatar* } \\
\text { Less than I }\end{array}$ & $115(8.1)$ & II (0.8) \\
I-5 & $718(50.7)$ & \\
6-I0 & $211(14.9)$ & \\
II-15 & $220(15.5)$ & \\
I6-20 & $86(6.1)$ & \\
More than 20 & $54(3.8)$ & \\
\hline Years since graduation with a & & $19(1.3)$ \\
professional degree* & & \\
Less than I & $1(0.1)$ & \\
I-5 & $122(8.6)$ & \\
6-I0 & $514(36.3)$ & \\
II-I5 & $320(22.6)$ & \\
I6-20 & $237(16.7)$ & \\
More than 20 & $202(14.3)$ & \\
\hline
\end{tabular}

Note: *Some missing data.

(91.02-97.90\%) to all of the statements in this domain (Table 3, Sub-scale 1).

\section{Subscale-2 Sense of Professional Identity}

Professional identity is defined as: "the attitudes, values, knowledge, beliefs and skills shared with others within a professional group". ${ }^{39}$ It refers to the professional status each healthcare professionals aspire to maintain about their profession. ${ }^{40}$ This subscale consisted of five negative statements to measure participants' sense of professional identity. Interestingly, the results of this subscale were inconsistent with the other subscales. To illustrate this point, $36.9 \%(\mathrm{n}=469 / 1270)$ of the participants agreed and $10.3 \%(n=131 / 1270)$ of them strongly agreed with the statement of "I have to acquire much more knowledge and skills than other healthcare professionals". Additionally, the statement "There is little overlap between my roles and that of other healthcare professionals" had $38 \% \quad(\mathrm{n}=485 / 1275)$ agreement and 8.4\% $(\mathrm{n}=107 / 1275)$ strong agreement (Table 3, Sub-scale 2). The percentage of participants who agreed and disagreed with the statement "Clinical problem-solving skills should only be learned with professionals from my own discipline" was almost the same (8\% strongly disagreed, $34.4 \%$ disagreed, $35.5 \%$ agreed, and $11.1 \%$ strongly agreed). However, a 
Table 2 Experience About Interprofessional Education and Collaborative Practice Among Healthcare Professionals in All Primary Health Centers in Qatar ( $=1415)$

\begin{tabular}{|c|c|}
\hline Items & Frequency (\%) \\
\hline \multicolumn{2}{|c|}{ How often do you interact with other healthcare professional? $(n=1329)$} \\
\hline Not at all & $6(0.5 \%)$ \\
\hline Somewhat & $137(10.3 \%)$ \\
\hline Quiet a lot & $175(13.2 \%)$ \\
\hline Regularly & 1011 (76\%) \\
\hline \multicolumn{2}{|c|}{ How often do you collaborate with other healthcare professional? $(n=\mid 323)$} \\
\hline Not at all & $14(1.1 \%)$ \\
\hline Somewhat & $190(14.4 \%)$ \\
\hline Quiet a lot & $272(20.56 \%)$ \\
\hline Regularly & $847(64.02 \%)$ \\
\hline \multicolumn{2}{|c|}{ Indicate the healthcare professionals you interact with? ${ }^{\dagger}(n=1323)$} \\
\hline Physician & II 64 (88\%) \\
\hline Nurse & $112 \mid(85 \%)$ \\
\hline Pharmacist & $934(71 \%)$ \\
\hline Others & $379(29 \%)$ \\
\hline Physiotherapist & $99(7.5 \%)$ \\
\hline \multicolumn{2}{|c|}{ Indicate the healthcare professionals you collaborate with? ${ }^{\dagger}(n=1323)$} \\
\hline Physician & $1165(89 \%)$ \\
\hline Nurse & $1096(84 \%)$ \\
\hline Pharmacist & $876(67 \%)$ \\
\hline Others & $222(17 \%)$ \\
\hline Physiotherapist & $97(7.4 \%)$ \\
\hline \multicolumn{2}{|c|}{ Have you participated in any interprofessional education activities? $(n=|3| 5)$} \\
\hline Yes & $1062(81 \%)$ \\
\hline No & $253(19 \%)$ \\
\hline \multicolumn{2}{|c|}{ Have you had any experience of collaborative practice? $(n=1290)$} \\
\hline Yes & $771(60 \%)$ \\
\hline No & $519(40 \%)$ \\
\hline
\end{tabular}

Note: ${ }^{\dagger}$ This question was a "multiple options response" type.

large proportion (18.5\% strongly disagree, $44 \%$ disagree) of the respondents disagreed with the statement "I would feel uncomfortable if another healthcare professional knew more about a topic than I did" (Table 3, Sub-scale 2).

\section{Subscale-3 Patient Centeredness}

Patient centeredness refers to patients being at the center of their care which means the patient-specific health needs and desired health outcomes are the driving force behind all healthcare decisions and quality measurements. Patients are partners with their healthcare providers. ${ }^{41}$ This subscale included five positive statements to measure participants' readiness to work in a patient-centered environment. The results of this section indicated readiness and positive attitudes towards being patient-centered professionals which were consistent with subscale 1 (Table 3, Sub-scale 3).

After analyzing the three domains of RIPLS, the Likert scale was converted to a quantitative measurement. For the sub-scales 1 and 3 where only positive statements were used, statements were ranked from the lowest to highest as "strongly disagree $=1$ " and "strongly agree $=5$ ". The subscale 2 contained negative statements, for which the reverse scoring was performed ("strongly agree $=1$ " to "strongly disagree $=5$ "), resulting in the generation of overall RIPLS scores for positive statements. 


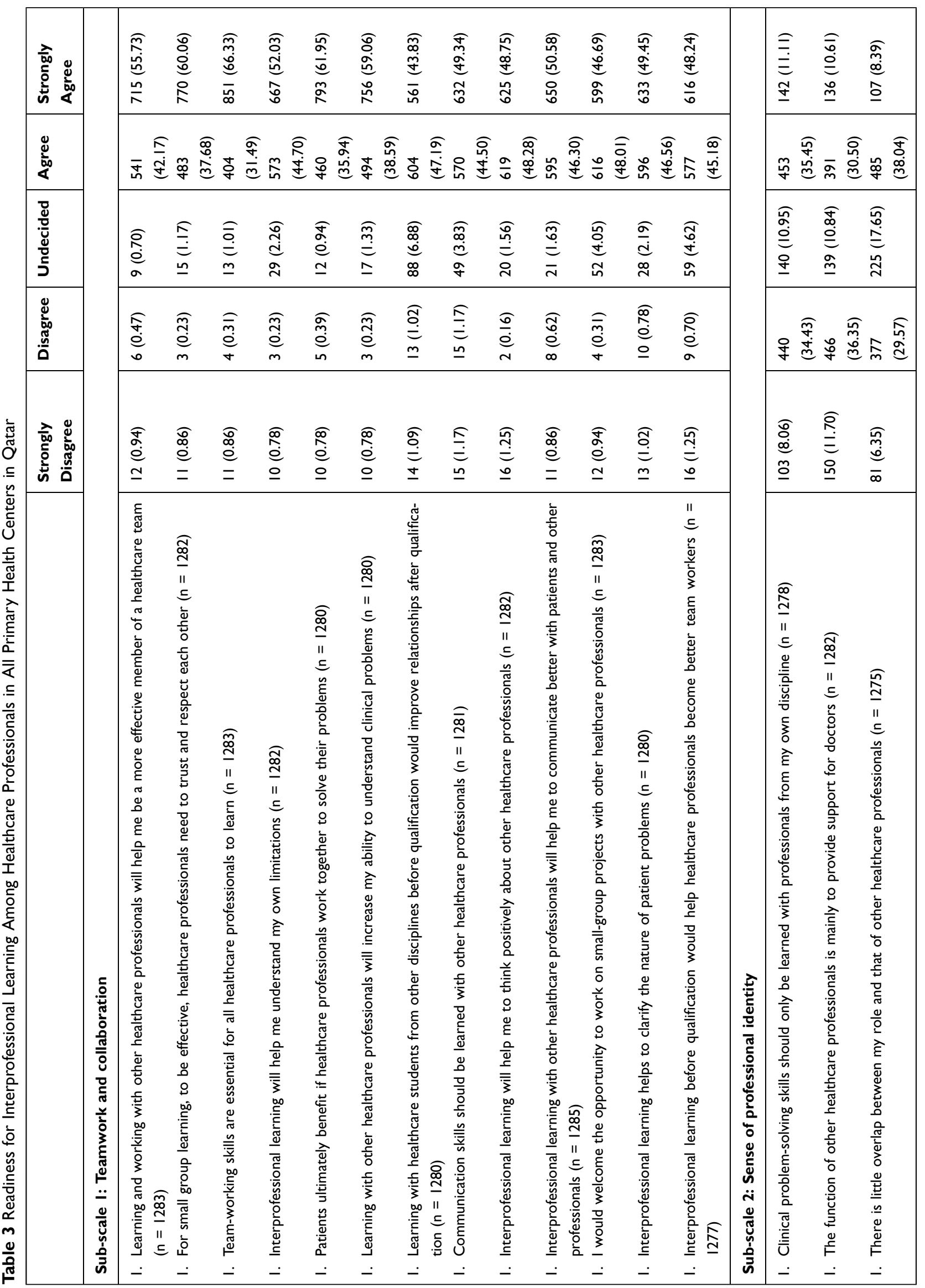




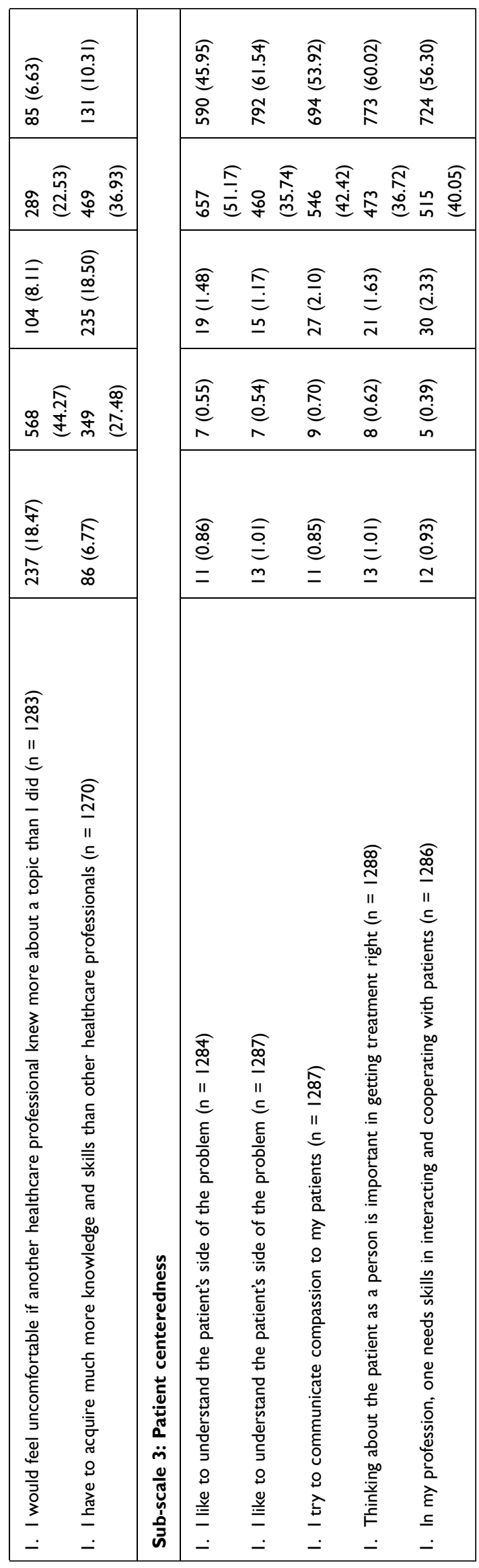

Student's $t$-test and One Way ANOVA test were performed to determine statistical differences in RIPLs scores between demographic groups (gender, age, profession, years of experience, country of first degree, previous participation in IPE and experience of collaborative practice) (Table 4). Female participants had a significantly greater positive attitude and readiness towards "teamwork and collaboration" than their male counterparts $(\mathrm{P}<0.001)$. However, gender did not show a significant effect on other subscales or total score of the RIPLS scale ( $P$ $>0.05$ ). Furthermore, participants aged 34 years or more had a significant effect on total RIPLS score than the other age groups ( $\mathrm{P}=0.02)$. Participants who had " $1-5$ years" of experience demonstrated more readiness towards "teamwork and collaboration" than other groups ( $\mathrm{P}<0.001)$. It was found that IPC experience had a statistically significant $(\mathrm{P}=0.007)$ impact on the sense of professional identity (subscale 2); however, no significant difference was found in other subscales.

\section{Beliefs About Interprofessional Collaboration}

The question "'How much is interprofessional collaboration important to your work?" was the highest-rated statement with $87.1 \%$ responding with quite a lot/consistently weighted average (WA: 4.25). On the other hand, "How much do other professionals understand the scope of your practice?" was the lowest-rated statement (WA: 3.49), indicating a lack of role clarity among different professionals.

\section{Interest in Interprofessional Learning}

Participants rated their interest in attending educational IPC training sessions. Most of the participants were interested in having a one-day-only workshop (WA: 2.71), followed by a two-day workshop (WA: 2.51). While the least favored mode of training was participating in a 3-credit hour university course (WA: 2.34). Participants also reported that time (WA: 3.58) was the main barrier to their participation in IPE followed by financial limitations (WA: 3.54), and lack of administrative support (WA: 3.33).

\section{Facilitators and Barriers Toward Collaborative Practice}

This section aimed to identify participants' perception about facilitators and barriers to IPC based on their 


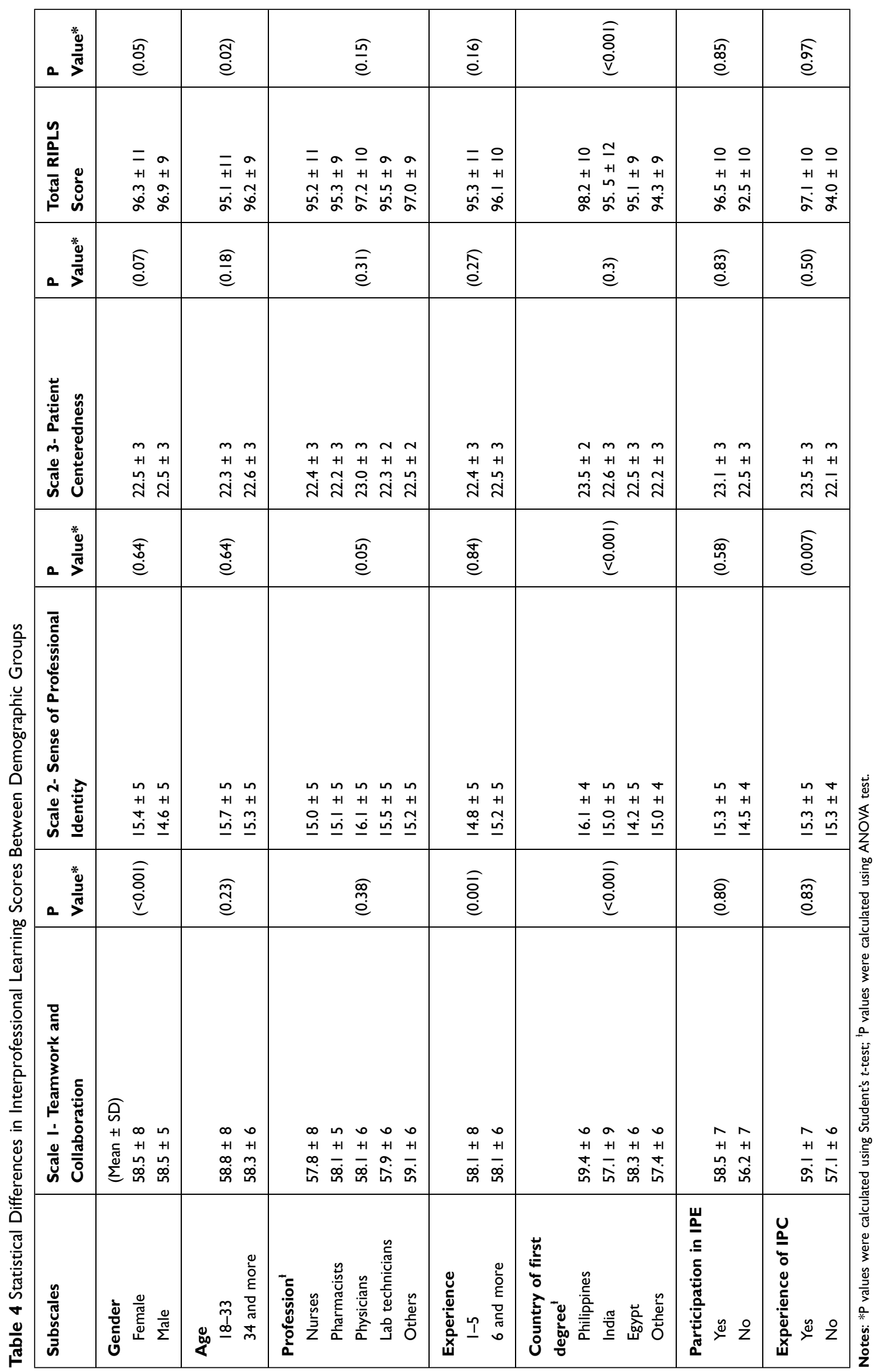


importance to them. HCP believed that "Increasing professional satisfaction" is the most important facilitator (WA: 3.69), followed by "Respecting the integrity and contribution of each profession" (WA: 3.68), and "Enhancing practice within the profession" (WA: 3.64). Conversely, "Encouraging professionals to learn with, from and about each other" (WA: 3.57) followed by "Focusing on the needs of patients and carers" (WA: 3.62) were the least important facilitators. For barriers, the highest-rated barrier was "leadership and support" (WA: 3.50), followed by "Time commitment" (WA: 3.45) and "Resources needed" (WA: 3.40). The least rated barrier was "hierarchy" (WA: 3.11 ) and "Resistance by healthcare professionals to collaborate" (WA: 3.23).

\section{Responses to Open-Ended Questions}

A thematic analysis was performed for the open-ended questions assessing participants' experiences and perceived facilitators and barriers to interprofessional learning and collaborative practice. Five main themes were identified: IPE experiences, impact of IPC on practice, facilitators and barriers to collaborative practice. These are highlighted in Table 5 with illustrative quotes.

\section{Discussion}

This research sheds light on the perspectives of HCP' toward IPC in primary care within a Middle Eastern setting. It also provided an insight into the facilitators and barriers toward IPC as perceived by over 1400 participants from over 10 healthcare professions with varying degrees of experiences and cultural backgrounds. Overall, HCP had a generally positive attitude and readiness towards IPC. Female HCP had a more positive attitude and readiness, which was significant, towards teamwork and collaboration than did male HCP though there was no significant difference in the effect on other subscales or total score. This is consistent with findings in other studies which showed that females were more positive about teamwork and collaboration than their male counterparts. ${ }^{42,43}$ Prior IPE experience was identified to positively influence attitude towards IPE and IPC. ${ }^{44}$ The stronger professional identity exhibited by physicians is consistent with other studies using the RIPLS scale. ${ }^{36,45,46}$ This could be attributed to the fact that many of the HCP have experienced a more traditional approach to medical education that is a discipline focused with less emphasis on IPC. ${ }^{36,45}$ However, there has been no link between stronger professional identity and less readiness to IPE. ${ }^{47}$ Self-identity is a transitional process and one that happens over time. It involves transforming "knowledge, skills, values and behaviors" that meld with that of one's' own unique identity and core values". 48 This sense of self owing to the formation of role identity within the team is said to have a positive effect on one's experience whilst collaborating on interprofessional healthcare teams.

Most participants rated their skills, in communication, building rapport and managing conflict, much higher than their knowledge level, and this observation is consistent with other studies using the same scale. ${ }^{29,37}$ This may lead to HCP reluctance to participate in training focused on skills enhancement even though these are important skills for collaboration. ${ }^{37}$ A study by Foronda et al, (2016) which looked at interprofessional communication in healthcare highlighted that both nurses and physicians are "trained differently and exhibit different communication styles". 49 Although in this study, most participants rated their level of communication as effective, however further results of Foronda's study have shown that nurses typically acquiesce to physicians and thus leads to disempowering their voice and hence ineffective communication practices. Ineffective communication practices in healthcare environments may lead to errors and impede treatment modalities (IPEC 2011). However, many of the participants were interested in IPC training despite the challenges of time, financial limitations and lack of administrative support. Training may include enhancing knowledge on team development, IPC models and research, as this was rated as the lowest among participants. IPE training is essential especially during the early stages of collaboration to improve attitude and collaborative skills and behavior needed for effective IPC and team working. ${ }^{50,51}$ Additionally, to overcome any challenges and obstacles that may hinder the process later on. ${ }^{20}$ One study about IPE in academic family medicine teaching units found that by pairing learners and teachers within practice units, having interprofessional led group activities and informal learning activities enabled healthcare staff to transition and evolve their practice whilst onsite in the clinical area which led to a shift in their professional socialization. ${ }^{52}$ Promisingly, within PHCC, a workforce development and training directorate runs continuing professional development for HCP in PHCC and these must include IPE development opportunities. In addition to this, organizational structures and strategies rewarding team performance need to be introduced to ensure the sustainability of team performance. ${ }^{51}$ 


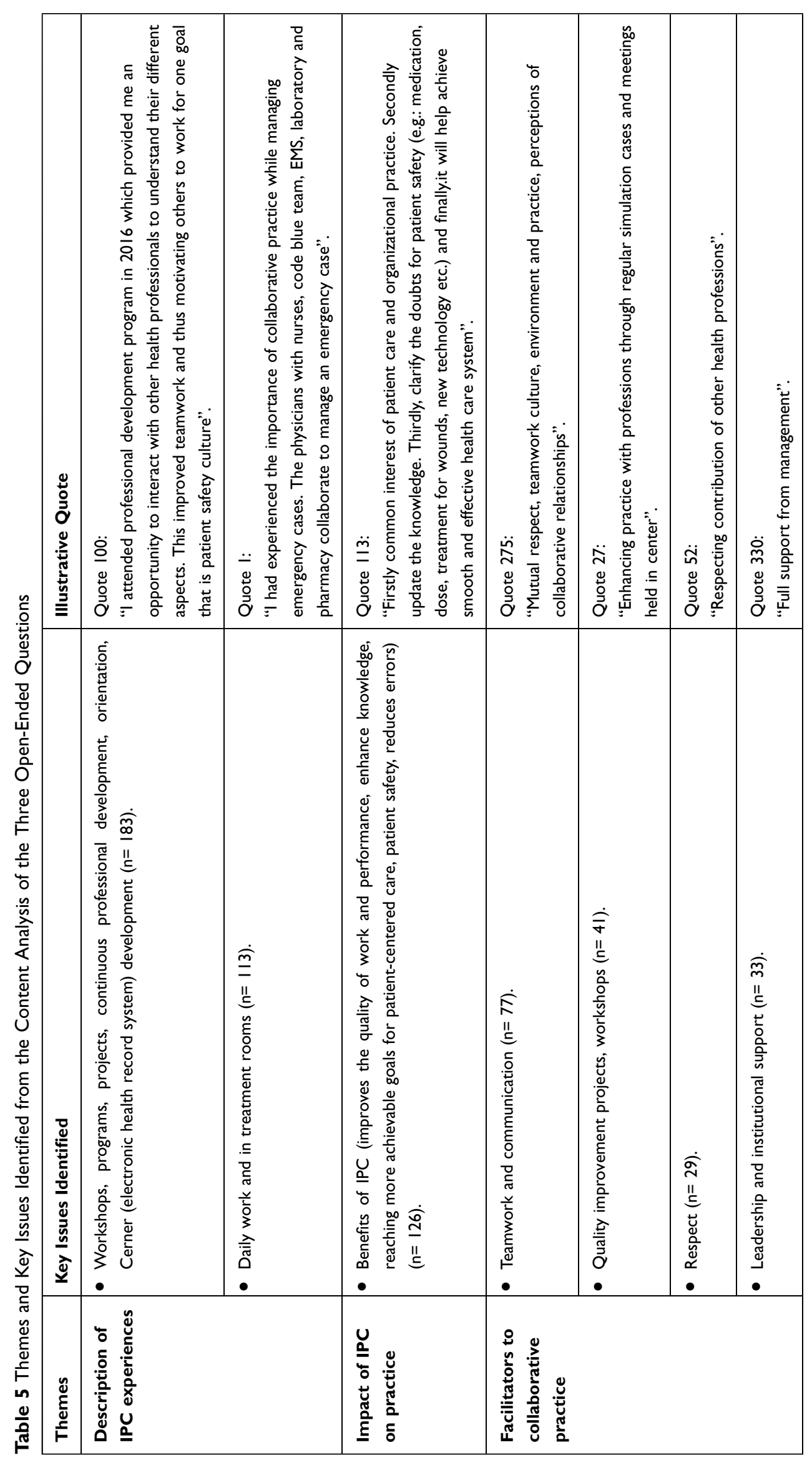




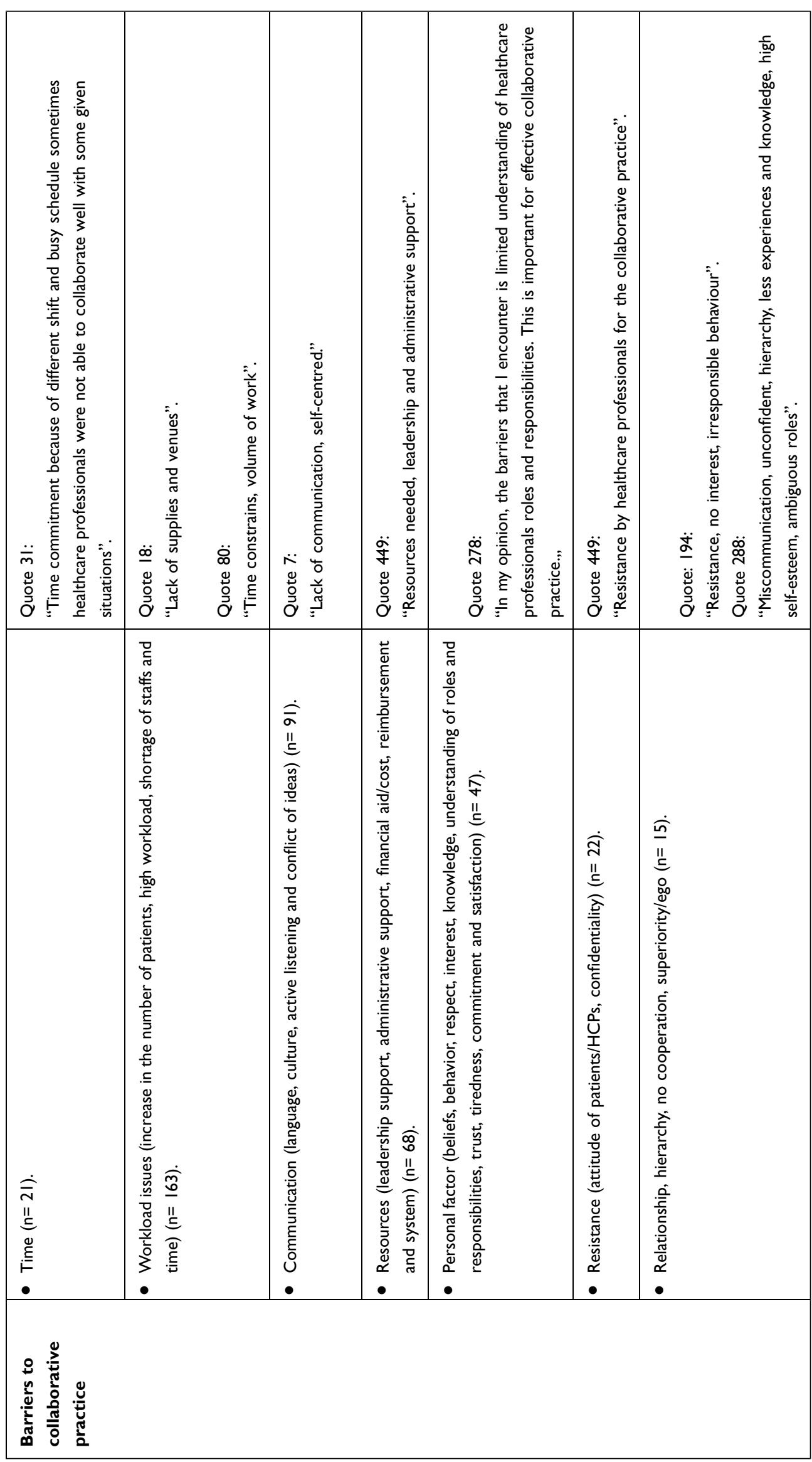


Facilitating factors for IPC, perceived by participants, were the positive attitude of HCP, the perceived benefit of IPC effectiveness in work setting, increased professional satisfaction, respect between healthcare professions, appreciation of other's contribution, leadership and institutional support. This is consistent with a systematic review that explored facilitators and barriers to IPC in primary care where facilitators were categorized into conceptual facilitating factors such as positive attitudes and perceived benefits of collaboration and structural facilitating factors that stem from working within the same organization and localized rather than centralized leadership. ${ }^{20}$ Currently, an assumption persists which purports that once graduated, healthcare personnel will effectively and easily collaborate as members of an interprofessional team. ${ }^{53}$ However, HCP need to make a transformative leap from doing or performing the role of healthcare practitioner to being a healthcare practitioner. ${ }^{54}$ In order to do this, they must be aware of models of IPE and the opportunity to engage into effect a smooth transition once graduated.

Although participants gave their highest rating to the effectiveness of IPC in their work settings, they were not as satisfied with the process of IPC in their work settings and the ability of other professionals to understand the scope of their practice. This is consistent with existing literature reporting barriers that inhibit IPC and lead to professional conflicts. ${ }^{20,51}$ An ultimate benefit from collaboration for PHC professionals is enhancing their professional role ${ }^{20}$ and thus there is a need for interprofessional training to enable participants the opportunity to understand the scope of practice of other professions within the healthcare realm.

Interestingly, hierarchy and resistance by HCP were rated the least in terms of barriers as usually hierarchy is amongst the top-rated barriers hindering collaboration. ${ }^{20,29}$ A possible explanation for this is HCP do not fully understand the concepts of collaboration especially as this has been recently implemented and introduced to primary care in Qatar. ${ }^{29}$ PHCC aims to be a leader in transforming the health and wellbeing of people's lives in Qatar and as a drive to improve the quality of primary care; they are currently Diamond Accredited by Accreditation Canada International (ACI). This has resulted in significant changes in quality improvement and a positive impact towards strengthening organizational learning level in the organization. ${ }^{55,56}$ In addition to being a driving change in promoting and implementing collaborative practices in PHCC. ${ }^{29}$ Furthermore, the recent PHCC strategic plan for
2019-2023 is geared towards transforming care through interprofessional teams providing a high-quality integrated family medicine model of care. One of the key principles of this model is that each patient will have a named general practitioner supported by an interprofessional team. ${ }^{56}$ However, it is important to note that collaboration is a complex process that needs sufficient time to enhance collaborative skills and invest in professional relations before forming functioning teams that are able to trust, respect and work collaboratively with each other. ${ }^{19,57}$ Collaboration among HCP needs to be intentional with the goal of creating and coordinating integrated patient-centered care plan through formal and social processes, team attitudes and team structure. ${ }^{18,58}$

\section{Strengths and Limitations}

Firstly, to our knowledge, this is the initial study to explore perspectives of HCP in primary care towards IPC from a Middle Eastern context. This provides a clear insight into IPC practice in the region and provides a base for other researchers with similar interests to build their objective on and align their findings to. Secondly, the study population included a number of HCP within one specific setting unlike existing literature which usually involves limited professions usually two in various settings. Moreover, the use of a survey as an outcome assessment tool added further strengths to this study; due to its anonymity nature which allowed participants to provide honest, unambiguous responses and reduced the risk of social desirability bias. Furthermore, the surveys were available in both web and paper-based forms to ensure the high accessibility of the surveys by our target population as well as considering participant's convenience.

In relation to study limitations, the following should be considered. Firstly, the risk of response bias was presented due to the extensively long survey (30 questions, 25-30 minutes). In addition, the survey was offered only in English which might be inconvenient for some HCP who may have favored an Arabic version. It is assumed that all HCP working in PHCC speak and understand English. Moreover, the inability to access a full list of all the participants hindered us from doing a simple random sampling technique to get a randomized population. However, the universal sample technique ensured the involvement of the whole population which would make the study of good generalizability. The participation was voluntary which may have led those with interest in IPC, with an element of social desirability, to fill the survey with a bias towards positive 
attitude and experiences. Nurses were the largest group in this study with lower response rates than all other HCP who work within the primary healthcare centers in Qatar. This may have biased the finding and the generalizability of the results. Mixed-mode survey using both paper-based and web-based survey led to a better response rate compared to our initial attempt of web-based survey only. Mixed-mode survey is known to have the highest response rate followed by web-based, and paper-based survey, respectively. ${ }^{59}$ Attitude to checking emails and answering surveys during the busy workday of HCP might have not been possible and it was easier for them to fill the paper-based copy. The initial low response rate with the survey could be attributed to the fact many HCP are still more comfortable with reading and recording data on paper than on screen. ${ }^{60,61}$ Further research is needed to examine these quantitative findings from a qualitative lens. This may provide insights into the interpretations of HCP toward IPC and the nature of collaboration in PHCC settings to ensure a comprehensive understanding is formed into what shapes these perspectives.

\section{Conclusion}

Recent reforms within the PHC setting consist of promoting interprofessional teams and collaborative culture. Given this, the PHC healthcare professional workforce needs to be able to respond and work in alignment with the PHC strategic plan to ensure effective interprofessional teams are formed with positive outcomes to the HCP, the interprofessional team, the patient and the organization. Taken together, in primary healthcare environments, it is imperative that interprofessional teams interdigitate to come to successful resolutions and formulate patient-centered goals. In order to achieve this, it is imperative to provide training and education to both foster and support interprofessional collaborative practice. Overall, HCP have demonstrated a willingness and readiness to engage with IPC with a number of facilitators and barriers identified with a desire for more training to enhance their delivery of care. Furthermore, in order to facilitate IPC, it is necessary that there is role clarification, delineation and respect for one's autonomy and profession be at the forefront when practicing as a collaborative cohesive team that has patients at its core.

\section{Ethical Approval}

Ethics approval was obtained from the Research Section of the PHCC (SCH-PHCC-IRB-087) and the Qatar University Institutional Review Board (QU-IRB 814-E/ 17).

\section{Acknowledgments}

The authors wish to thank all the healthcare professionals who completed the survey and participated in this research. Open Access funding was provided by the Qatar National Library.

\section{Disclosure}

The authors of this manuscript have no conflicts of interest to declare.

\section{References}

1. World Health Organisation. Framework for Action on Interprofessional Education and Collaborative Practice; 2010.

2. Hojat M, Ward J, Spandorfer J, Arenson C, Van Winkle LJ, Williams B. The jefferson scale of attitudes toward interprofessional collaboration (JeffSATIC): development and multi-institution psychometric data. J Interprof Care. 2015;29(3):238-244. doi:10.3109/ 13561820.2014.962129

3. El-Awaisi A, Diack L, Joseph S, El Hajj M. Perspectives of pharmacy students, pharmacy academics and practicing pharmacists on interprofessional education and collaborative practice: a comprehensive systematic review protocol. JBI Database Systematic Rev Implementation Rep. 2016;13(12):70-92. doi:10.11124/jbisrir-20152115

4. Macdonald MB, Bally JM, Ferguson LM, Lee Murray B, FowlerKerry SE, Anonson JMS. Knowledge of the professional role of others: a key interprofessional competency. Nurse Educ Pract. 2010;10(4):238-242. doi:10.1016/j.nepr.2009.11.012

5. Bassendowski S, Stevenson K, Wagner SJ, et al. A National Interprofessional Competency Framework. Vancouver: Canadian Interprofessional Health Collaborative. 2010. Available from: http:// ipcontherun.ca/wp-content/uploads/2014/06/National-Framework. pdf.

6. WHO. Framework for Action on Interprofessional Education and Collaborative Practice; 2010.

7. Buring SM, Bhushan A, Brazeau G, Conway S, Hansen L, Westberg S. Keys to successful implementation of interprofessional education: learning location, faculty development, and curricular themes. Am J Pharm Educ. 2009;73:4. doi:10.5688/aj730460

8. Baker L, Egan-Lee E, Martimianakis MA, Reeves S. Relationships of power: implications for interprofessional education. J Interprof Care. 2011;25(2):98-104. doi:10.3109/13561820.2010.505350

9. Reeves S, Fletcher S, Barr H, et al. A BEME systematic review of the effects of interprofessional education: BEME Guide No. 39. Med Teach. 2016;38:1-13. doi:10.3109/0142159x.2016.1173663

10. (FIP) IPF. Interprofessional education in a pharmacy context: global report; 2015. Available from: http://fip.org/files/fip/ PharmacyEducation/IPE_report/FIPEd_IPE_report_2015_web_v3. pdf

11. Capella J, Smith S, Philp A, et al. Teamwork training improves the clinical care of trauma patients. J Surg Educ. 2010;67(6):439-443. doi:10.1016/j.jsurg.2010.06.006

12. Denham CR, Dingman J, Foley ME, et al. Are you listening ... are you really listening? J Patient Saf. 2008;4(3):148-161. doi:10.1097/ PTS.0b013e318184db52

13. Mickan SM. Evaluating the effectiveness of health care teams. Aust Health Rev. 2005;29(2):211-217. doi:10.1071/AH050211

14. Zwarenstein M, Reeves S. Knowledge translation and interprofessional collaboration: where the rubber of evidence-based care hits the road of teamwork. J Contin Educ Health Prof. 2006;26(1):46-54. doi:10.1002/chp.50. 
15. Samuelson M, Tedeschi P, Aarendonk D, de la Cuesta C, Groenewegen P. Improving interprofessional collaboration in primary care: position paper of the European forum for primary care. Qual Prim Care. 2012;20(4):303-312.

16. Pullon S, Morgan S, Macdonald L, McKinlay E, Gray B. Observation of interprofessional collaboration in primary care practice: A multiple case study. J Interprof Care. 2016;30(6):787-794. doi:10.1080/ 13561820.2016.1220929

17. Starfield B, Shi L, Macinko J. Contribution of primary care to health systems and health. Milbank Q. 2005;83(3):457-502. doi:10.1111/ j.1468-0009.2005.00409.x

18. Mulvale G, Embrett M, Razavi SD. 'Gearing Up' to improve interprofessional collaboration in primary care: a systematic review and conceptual framework. BMC Fam Pract. 2016;17:83. doi:10.1186/ s12875-016-0492-1

19. Lawn S, Lloyd A, King A, Sweet L, Gum L. Integration of primary health services: being put together does not mean they will work together. BMC Res Notes. 2014;7(1):66. doi:10.1186/1756-0500-7-66

20. Supper I, Catala O, Lustman M, Chemla C, Bourgueil Y, Letrilliart L. Interprofessional collaboration in primary health care: a review of facilitators and barriers perceived by involved actors. J Public Health. 2015;37(4):716-727. doi:10.1093/pubmed/fdu102

21. Wranik WD, Price S, Haydt SM, et al. Implications of interprofessional primary care team characteristics for health services and patient health outcomes: A systematic review with narrative synthesis. Health Policy. 2019;123(6):550-563. doi:10.1016/j.healthpol.2019.03.015

22. Perreault K, Pineault R, Da Silva RB, Provost S, Feldman DE. What can organizations do to improve family physicians' interprofessional collaboration? Results of a survey of primary care in Quebec. Can Fam Physician. 2017;63(9):e381-e388.

23. Zheng RM, Sim YF, Koh GC. Attitudes towards interprofessional collaboration among primary care physicians and nurses in Singapore. J Interprof Care. 2016;30(4):505-511. doi:10.3109/ 13561820.2016.1160039

24. Hughes CM, McCann S. Perceived interprofessional barriers between community pharmacists and general practitioners: a qualitative assessment. British J General Practice. 2003;53(493):600-606.

25. Elsous A, Radwan M, Nurses MS. Physicians attitudes toward nursephysician collaboration: a survey from gaza strip, Palestine. Nurs Res Pract. 2017;2017:7406278. doi:10.1155/2017/7406278

26. Hashemian F, Emadi F, Roohi E. Collaboration between pharmacists and general practitioners in the health care system in the Islamic Republic of Iran. Eastern Mediterranean Health Journal. 2016;22(6). doi:10.26719/2016.22.6.375

27. Hasan S, Stewart K, Chapman CB, Kong DCM. Physicians' perspectives of pharmacist-physician collaboration in the United Arab Emirates: findings from an exploratory study. $J$ Interprof Care. 2018;32(5):566-574. doi:10.1080/13561820.2018.1452726

28. Albassam A, Almohammed H, Alhujaili M, Koshy S, Awad A. Perspectives of primary care physicians and pharmacists on interprofessional collaboration in Kuwait: A quantitative study. PLoS One. 2020;15(7):e0236114. doi:10.1371/journal.pone.0236114

29. El-Awaisi A, El Hajj MS, Joseph S, Diack L. Perspectives of practising pharmacists towards interprofessional education and collaborative practice in Qatar. Int J Clin Pharm. 2018;40:1388-1401. doi:10.1007/s11096-018-0686-9

30. Wilbur K, Beniles A, Hammuda A. Physician perceptions of pharmacist roles in a primary care setting in Qatar. Global Health. 2012;8:12. doi:10.1186/1744-8603-8-12

31. Zaidan M, Singh R, Wazaify M, Tahaineh L. Physicians' perceptions, expectations, and experience with pharmacists at hamad medical corporation in Qatar. $J$ Multidiscip Healthc. 2011;4:85-90. doi:10.2147/JMDH.S14326

32. El-Awaisi A, Wilby KJ, Wilbur K, et al. Eastern journey of integrating interprofessional education into the healthcare curriculum: a SWOC analysis. BMC Med Educ. 2017;17(1):15. doi:10.1186/ s12909-016-0852-5
33. Ditta MA, Ahmed B. The development of a primary health care system in the state of Qatar. World. 2019.

34. Ministry of Public Health. National health strategy 2018-2022: our health, our future. Ministry of Public Health; 2019. Available from: https://www.moph.gov.qa/HSF/Documents/short\%20report $\% 20$ eng\% 2020.03.2018.pdf. Accessed July 01, 2019

35. Wilbur K. Pharmacovigilance in Qatar Hospitals. Pharmaceut Med. 2012;26(1):23-25. doi:10.1007/BF03256889

36. Reid R, Bruce D, Allstaff K, McLernon D. Validating the Readiness for Interprofessional Learning Scale (RIPLS) in the postgraduate context: are health care professionals ready for IPL? Med Educ. 2006;40(5):415-422. doi:10.1111/j.1365-2929.2006.02442.x

37. Baerg K, Lake D, Paslawski T. Survey of interprofessional collaboration learning needs and training interest in health professionals, teachers, and students: an exploratory study. J Res Interprofessional Practice Education. 2012;2(2). doi:10.22230/jripe.2012v2n2a47

38. Lavrakas PJ. Encyclopedia of survey research methods. Sage Publications. 2008.

39. Adams K, Hean S, Sturgis P, Clark JM. Investigating the factors influencing professional identity of first-year health and social care students. Learning Health Social Care. 2006;5(2):55-68. doi:10.1111/j.1473-6861.2006.00119.x

40. Parsell G, Bligh J. The development of a questionnaire to assess the readiness of health care students for interprofessional learning (RIPLS). Med Educ. 1999;33(2):95-100. doi:10.1046/j.13652923.1999.00298.x

41. Catalyst N. What is patient-centered care? NEJM Catalyst. 2017;3:1.

42. Wilhelmsson M, Ponzer S, Dahlgren L-O, Timpka T, Faresjö T. Are female students in general and nursing students more ready for teamwork and interprofessional collaboration in healthcare? BMC Med Educ. 2011;11:15. doi:10.1186/1472-6920-11-15

43. Hansson A, Foldevi M, Mattsson B. Medical students' attitudes toward collaboration between doctors and nurses - a comparison between two Swedish universities. J Interprof Care. 2010;24 (3):242-250. doi:10.3109/13561820903163439

44. O'Carroll V, McSwiggan L, Campbell M. Health and social care professionals' attitudes to interprofessional working and interprofessional education: A literature review. J Interprof Care. 2016;30 (1):42-49. doi:10.3109/13561820.2015.1051614

45. Morison S, Boohan M, Moutray M, Jenkins J. Developing prequalification inter-professional education for nursing and medical students: sampling student attitudes to guide development. Nurse Educ Pract. 2004;4(1):20-29. doi:10.1016/s1471-5953(03)000155

46. El-Zubeir M, Rizk DE, Al-Khalil RK. Are senior UAE medical and nursing students ready for interprofessional learning? Validating the RIPL scale in a middle eastern context. J Interprof Care. 2006;61932(vol):6.

47. Visser CLF, Wilschut JA, Isik U, van der Burgt SME, Croiset G, Kusurkar RA. The association of readiness for interprofessional learning with empathy, motivation and professional identity development in medical students. BMC Med Educ. 2018;18(1):125. doi:10.1186/s12909-018-1248-5

48. Wald HS. Professional identity (trans) formation in medical education: reflection, relationship, resilience. Acad Med. 2015;90(6):701706. doi:10.1097/acm.0000000000000731

49. Foronda C, MacWilliams B, McArthur E. Interprofessional communication in healthcare: an integrative review. Nurse Educ Pract. 2016;19:36-40. doi:10.1016/j.nepr.2016.04.005

50. Robben S, Perry M, van Nieuwenhuijzen L, et al. Impact of interprofessional education on collaboration attitudes, skills, and behavior among primary care professionals. J Contin Educ Health Prof. 2012;32(3):196-204. doi:10.1002/chp.21145

51. Xyrichis A, Lowton K. What fosters or prevents interprofessional teamworking in primary and community care? A literature review. Int J Nurs Stud. 2008;45(1):140-153. doi:10.1016/j.ijnurstu.2007.01.015 
52. Price D, Howard M, Hilts L, et al. Interprofessional education in academic family medicine teaching units: a functional program and culture.. Can Fam Physician. 2009;55(9):1-901.

53. Honan L, Fahs DB, Talwalkar JS, Kayingo G. Interprofessional learning: perceptions of first year health students. $J$ Nursing Education Practice. 2015;5(6):39-49.

54. Jarvis-Selinger S, Pratt DD, Regehr G. Competency is not enough: integrating identity formation into the medical education discourse. Acad Med. 2012;87(9):1185-1190. doi:10.1097/ACM.0b013e3182604968

55. Ghareeb A, Said H, El Zoghbi M. Examining the impact of accreditation on a primary healthcare organization in Qatar. BMC Med Educ. 2018;18(1):216. doi:10.1186/s12909-018-1321-0

56. PHCC. Primary Health Care Corporation Corporate Strategic Plan (2019 - 2023): A Healthier Future for Our Families; 2019.

57. Sørensen M, Stenberg U, Garnweidner-Holme L, Scoping A. Review of facilitators of multi-professional collaboration in primary care. Int J Integr Care. 2018;18(3):13. doi:10.5334/ijic.3959
58. Morgan KH, Barroso CS, Bateman S, Dixson M, Brown KC Patients' experiences of interprofessional collaborative practice in primary care: a scoping review of the literature. $J$ Patient Experience. 2020;2374373520925725.

59. Greenlaw C, Brown-Welty S. A comparison of web-based and paperbased survey methods: testing assumptions of survey mode and response cost. Eval Rev. 2009;33(5):464-480. doi:10.1177/ $0193841 \times 09340214$

60. Taylor T, Scott A. Do physicians prefer to complete online or mail surveys? Findings from a national longitudinal survey. Eval Health Prof. 2019;42(1):41-70. doi:10.1177/0163278718807744

61. Wyatt JC. When to use web-based surveys. JAMIA. 2000;7(4):426429. doi:10.1136/jamia.2000.0070426
Journal of Multidisciplinary Healthcare

\section{Publish your work in this journal}

The Journal of Multidisciplinary Healthcare is an international, peerreviewed open-access journal that aims to represent and publish research in healthcare areas delivered by practitioners of different disciplines. This includes studies and reviews conducted by multidisciplinary teams as well as research which evaluates the results or conduct of such teams or healthcare processes in general. The journal

\section{Dovepress}

covers a very wide range of areas and welcomes submissions from practitioners at all levels, from all over the world. The manuscript management system is completely online and includes a very quick and fair peer-review system. Visit http://www.dovepress.com/testimonials. php to read real quotes from published authors. 